\title{
Influence of preoperative radiotherapy on DNA ploidy in squamous cell carcinomas of the oesophagus
}

\author{
R Porschen, G Bevers, U Remy, S Schauseil, F Borchard
}

\begin{abstract}
The influence of preoperative radiotherapy on the prevalence of DNA aneuploidy and the prognostic significance of tumour DNA ploidy was evaluated in 126 patients with squamous cell carcinoma of the oesophagus. Preoperative radiotherapy with $\mathbf{3 0} \mathbf{G y}$ was performed in 52 patients. DNA ploidy was analysed by flow cytometry on nuclei isolated from parafin embedded tumour tissue. DNA aneuploidy was identified in 75 tumours $(61 \%)$ and found to correlate significantly with tumour stage. The percentage of aneuploid carcinomas was significantly reduced by preoperative radiotherapy (surgery only group, $71 \%$; radiotherapy group, 47\%, $\mathrm{p}=0.01$ ). Although the median survival time was slightly better in the diploid than in the aneuploid group (11.3 and 8.0 months respectively), this difference was not statistically significant. A curative tumour resection was the most important prognostic factor. Preoperative radiotherapy did not prolong survival in oesophageal cancer.

(Gut 1993; 34: 1086-1090)
\end{abstract}

Despite efforts at early diagnosis and advances in surgery, radiation therapy, and chemotherapy, the prognosis of squamous cell carcinoma of the oesophagus remains poor. Because chromosomal aberrations are a marker of malignancy and have been shown to correlate with changes in DNA content, DNA flow cytometry is widely used in the analysis of neoplasia. ${ }^{1}$ Several studies on gastrointestinal cancers ${ }^{2-4}$ have shown that flow cytometric detection of an abnormal DNA content may provide additional prognostic information.

The objective of this flow cytometric study was to evaluate the impact of preoperative radiotherapy on the prevalence of DNA aneuploidy and to analyse the prognostic significance of DNA ploidy in oesophageal squamous cell cancer.

Gastroenterology,

R Porschen

$G$ Bevers

U Remy

Institute of Laboratory

Medicine and Pathology,

Heinrich-Heine-

University, Düsseldorf,

Germany

S Schauseil

F Borchard

Correspondence to:

R Porschen, MD, PhD,

Department of

Gepartment of

Medicine, Heinrich-Heine-

Medicine, Heinrich-Hein,

University, Moorenstr

Germany.

Accepted for publication

8 December 1992
One hundred and twenty six patients (103 men, 23 women) with a squamous cell carcinoma of the oesophagus treated at the Department of Surgery of the Heinrich-Heine-University until December 1986 entered the study. Mean (SD) age of the patients was $56 \cdot 2$ (SD 9.9) years. In 86 patients, complete resection of the tumour was performed. In 52 patients, radiotherapy with 30 Gy was performed before surgery. The mean time interval between completion of radiation treatment and surgery was 10 days. At the end of the study 119 patients had died.

All histological tumour sections were reclassified according to the 1987 updated TNF classification by one of the authors (FB). Table I shows tumour characteristics. Tumour length ranged from 0.5 to $13 \mathrm{~cm}$ (median, $3.0 \mathrm{~cm}$ ).

\section{FLOW CYTOMETRY}

Formalin fixed, paraffin embedded tumour tissue was prepared and stained for flow cytometric analysis according to the slightly modified procedure described by Hedley et al. ${ }^{5}$ To decrease nuclear debris ${ }^{6}$ sections of $80 \mu \mathrm{m}$ were cut from tumour blocks stored at the Department of Pathology. Sections were deparaffinised by treatment with xylene overnight, rehydrated through a series of graded ethanol solutions and washed with distilled water.

A nuclear suspension was prepared by incubating the sections in $0.5 \%$ pepsin (Sigma, St Louis, Missouri) in $0.9 \% \mathrm{NaCl}$ solution ( $\mathrm{pH}$ $1.5 ; 37^{\circ} \mathrm{C}$ ). After filtration through a $50 \mu \mathrm{m}$ nylon mesh nuclei were washed twice with phosphate buffered saline. The sediment was resuspended in a $0 \cdot 1 \%$ Nonidet $P 40$ - trisodium citrate solution. ${ }^{7}$ After addition of ribonuclease A (Sigma, St Louis, Missouri; final concentration $0.1 \%$ ) nuclear DNA was stained with propidium iodide (Sigma, St Louis, Missouri; 50 $\mu \mathrm{g} / \mathrm{ml}$ ).

TABLE I Tumour characteristics of irradiated and unirradiated squamous cell carcinomas of the oesophagus

\begin{tabular}{lc} 
& $N o(\%)$ \\
\hline Tumour site: & \\
Upper third & $17(13 \cdot 5)$ \\
Mid-third & $70(55 \cdot 5)$ \\
Lower third & $34(27 \cdot 0)$ \\
>One third & $5(4 \cdot 0)$ \\
Grading: & $12(9 \cdot 5)$ \\
G1 & $77(61 \cdot 1)$ \\
G2 & $33(26 \cdot 2)$ \\
G3 & $4(3 \cdot 2)$ \\
G4 & $10(7 \cdot 9)$ \\
Tumour invasion: & $22(17 \cdot 5)$ \\
pT1 & $65(51 \cdot 6)$ \\
pT2 & $29(23 \cdot 0)$ \\
pT3 & \\
pT4 & $54(42 \cdot 9)$ \\
Lymph node metastasis: & $72(57 \cdot 1)$ \\
pN0 & \\
pN1 & $107(84 \cdot 9)$ \\
Distant metastasis: & $19(15 \cdot 1)$ \\
M0 & \\
M1 & $9(7 \cdot 1)$ \\
Tumour stage: & $47(37 \cdot 3)$ \\
I & $51(40 \cdot 5)$ \\
II & $19(15 \cdot 1)$ \\
II & \\
IV & \\
\hline
\end{tabular}


Nuclear DNA content of at least 10000 tumour cells in each block were measured with an EPICS C flow cytometer. One to six paraffin embedded blocks were measured for each patient (mean 2.5 blocks). Two to three sections were measured in each block. In three patients, no analysable DNA histogram could be generated because their tumours had been fixed in Bouin's solution.

Tumours were either classified as diploid or aneuploid. Samples with more than one $G_{0} / G_{1}$ peak in the DNA histogram were judged as aneuploid. ${ }^{8}$ In these tumours, the first peak on the left of the histogram was considered to represent diploid $G_{0} / G_{1}$ cells. For DNA aneuploid samples a DNA index was calculated as the ratio of the abnormal $G_{0} / G_{1}$ mean peak channel number to the diploid $G_{0} / G_{1}$ mean peak channel number. Histograms were classified without previous knowledge of the pathological or survival data.

We restricted our flow cytometric analysis to the determination of DNA ploidy because increased amounts of nuclear fragments after enzymatic digestion reduce the accuracy of cell cycle analysis accounting for the relatively poor correlation between proliferative activity in unfixed compared with paraffin embedded material..$^{10}$ Furthermore, because of the higher coefficient of variation in paraffin embedded material cell cycle analysis is not as reliable as in fresh tissue of solid tumours. The mean (SD) coefficient of variation of the $G_{1}$ peak in this study was $5 \cdot 9 \%(1 \cdot 5 \%$ ) (range $3 \cdot 6 \%$ to $8 \cdot 8 \%$ ).

\section{STATISTICS}

Frequency tables were analysed by the $\chi^{2}$ test. Survival time was defined as the period between surgery and death. Three patients were lost to follow up and have been excluded from the analysis of survival. Patients dying as a result of postoperative complications (within 30 days) were excluded from the survival analysis. Univariate survival analysis was performed with the BMDP 1L computer program by the life table method." Data are presented as median (SEM). The significance of differences was calculated with the generalised Wilcoxon test (Breslow) and the generalised Savage test (Mantel-Cox).

The Cox proportional hazard model ${ }^{12}$ was used in multivariate regression analyses of survival data (BMDP 2L). Variables entered into the model were sex of the patients, age of the patients $(<60 ;>60$ years), tumour site, tumour grading, tumour stage, radicality of surgery, radiotherapy, DNA ploidy, and tumour length $(<3 \mathrm{~cm} ;>3 \mathrm{~cm})$.

\section{Results}

\section{DNA PLOIDY}

DNA diploidy was detected in 48 cancers of the oesophagus (39\%) and aneuploidy in 75 tumours (61\%). In four patients, more than one aneuploid peak was present. The DNA indices ranged from $1 \cdot 0$ to $2 \cdot 64$.

Tumour DNA content was not significantly
TABLE II Relation between DNA ploidy and clinical and pathological variables in 123 patients with a squamous cell carcinoma of the oesophagus

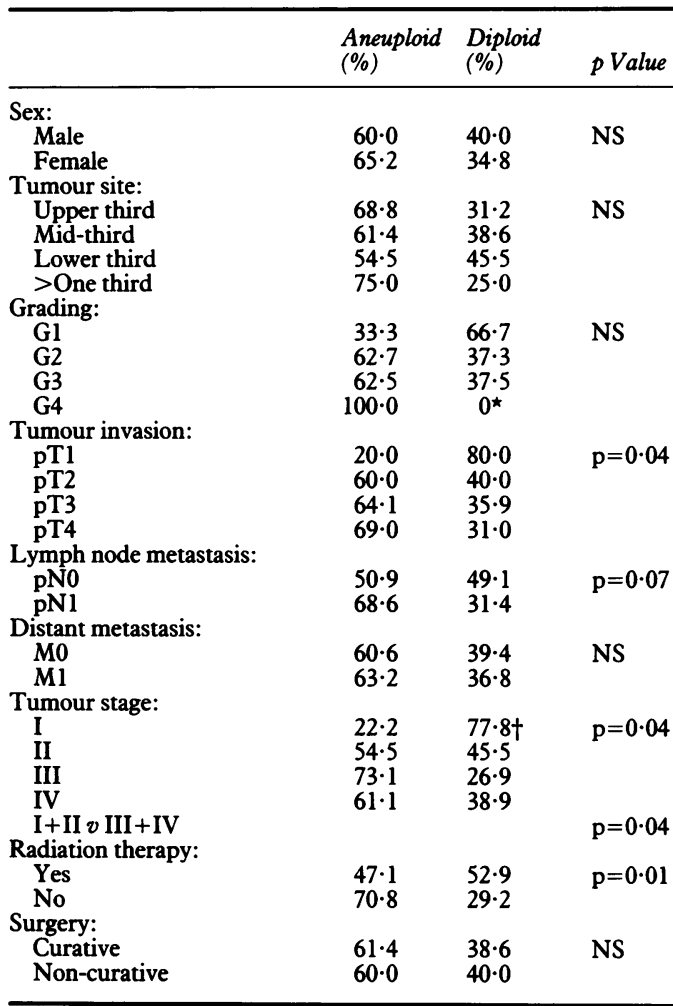

^This group contained four patients. There was no significan difference after testing $\mathrm{Gl} / 2 v \mathrm{G} 3 / 4$. TThe aneuploid group in stage I contained only two patients. The analysis was therefore repeated for tumour stage I+II $v$ III + IV

related to gender of the patients, tumour site, or tumour differentiation (Table II). DNA ploidy significantly correlated with the invasion of the primary tumour. The percentage of aneuploid tumours rose from $20 \%$ in T1 tumours to $69 \%$ in T4 tumours. The percentage of diploid carcinomas was significantly higher in stage I and II tumours $(51 \%)$ than in stage III and IV tumours (30\%). The association with lymph node metastasis was of borderline statistical significance $(p=0 \cdot 07)$. DNA ploidy did not influence the result of surgery (curative $v$ non-curative).

Prevalence of DNA aneuploidy, however, was significantly influenced by preoperative radiotherapy. The percentage of aneuploid tumours decreased from $71 \%$ in unirradiated tumours to $47 \%$ in irradiated tumours $(\mathrm{p}=0.01)$. Tumour diameter decreased from $4 \cdot 2(2 \cdot 8) \mathrm{cm}$ to $3 \cdot 1(1 \cdot 6)$ $\mathrm{cm}$ after irradiation $(\mathrm{p}=0 \cdot 02)$. Preoperative radiotherapy did not change the percentage of curative resections.

\section{SURVIVAL}

After exclusion of postoperative deaths the overall five year survival rate was $6 \cdot 5 \%$. Median survival time of the whole study population $(n=$ 101) was $9 \cdot 2(1 \cdot 4)$ months.

In univariate survival analysis the presence of lymph node metastasis (N0: median survival, 13.8 months; N1: $7 \cdot 3$ months), the presence of distant metastasis (M0: 10.6 months; $M 1$ : 6.0 months), and tumour stage (I: 51.6 months; II: 11.8 months; III: 8.3 months; IV: 6.0 months) were highly significant prognostic variables for 


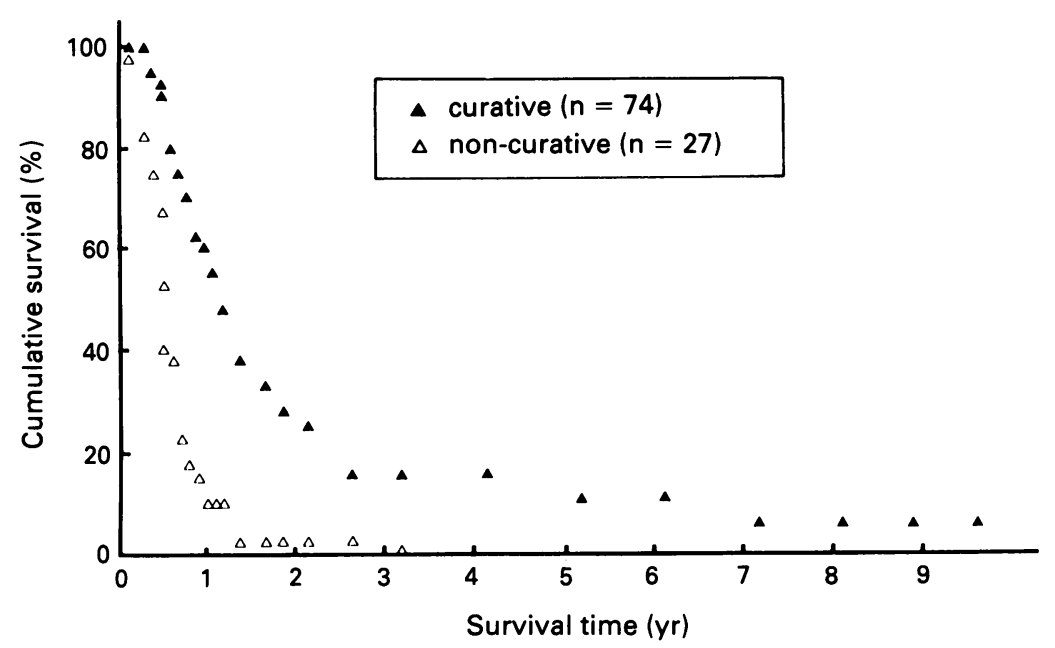
Figure 1: Survival of patients with squamous cell carcinomas of the oesophagus was
significantly influenced by the result of surgery $(p<0.0001$ by generalised Wilcoxon test and by generalised Savage test).

the whole study group. Radicality of surgery had a considerable influence on survival (curative resection: 11.8 months; non-curative: 4.6 months; Fig 1). One year after surgery, survival rate was $49 \%$ after curative resection in comparison to $11 \%$ after non-curative surgery.

Tumour grading and tumour invasion were of borderline statistical significance. Preoperative radiation treatment did not result in a significant prolongation of survival (surgery group 8.5 months; radiation plus surgery group $10 \cdot 5$ months). Female patients ( 15.0 months) tended to survive longer than male patients $(8.3$ months, NS). Patients with diploid tumours (median survival, $11 \cdot 3(1 \cdot 2)$ months) survived longer than patients with aneuploid tumours $(8 \cdot 0(1 \cdot 3)$ months). This difference in survival time was not significant (Fig 2).

These univariate survival analyses were also separately performed for the group of patients with preoperative radiotherapy and the group with surgery only. Radicality of surgery remained the most important survival factor. After surgery alone, patients with diploid tumours (15.0 (12.0) months) survived longer than patients with aneuploid tumours $(7 \cdot 3(0 \cdot 9)$

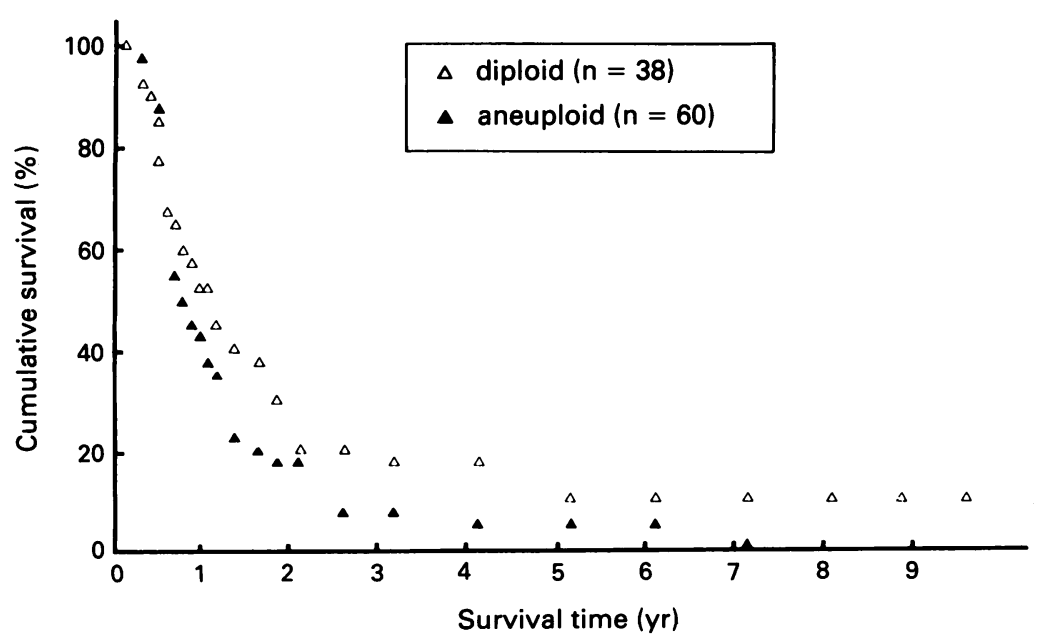

Figure 2: Survival of patients with carcinoma of the esophagus was not influenced by DNA ploidy state (life table analysis). months; $p=0.09$ by generalised Wilcoxon test, $p=0.06$ by generalised Savage test). In the radiotherapy group there was a non-significant DNA diploid survival advantage (19.5 (2.0) months $v 12 \cdot 0(2 \cdot 0)$ months).

After a curative tumour resection, female patients $(23 \cdot 1(4 \cdot 3)$ months) survived significantly longer than male patients $(11.2(0.9)$ months; $p=0.03$ by generalised Wilxocon test, $\mathrm{p}=0.05$ by generalised Savage test). Preoperative radiotherapy did not prolong the median survival time. DNA ploidy did not have a significant prognostic influence on survival after a curative resection.

When the prognostic impact of the different clinicopathological and flow cytometric variables on survival was evaluated in a multivariate regression analysis, radicality of surgery emerged as the most important factor $\left(\chi^{2}=22 \cdot 5\right)$ followed by tumour grading $\left(\chi^{2}=7 \cdot 1\right)$, sex of the patients $\left(\chi^{2}=7 \cdot 1\right)$, and tumour stage $\left(\chi^{2}=5 \cdot 0\right)$. DNA ploidy did not confer independent prognostic information for survival.

\section{Discussion}

Squamous cell carcinoma of the oesophagus remains one of the deadliest malignant neoplasms because patients often present with advanced disease at the time of diagnosis. The prognosis of patients with carcinoma of the oesophagus mainly depends on pathohistological and surgical criteria..$^{13-15}$ As in our study, their is a clear difference in survival between the curative and non-curative groups. In the multivatiate regression analysis, radicality of surgery was the most important prognostic variable. After the development of lymph node metastases and distant metastases, median survival of patients declined significantly. Our observation that female patients carry an improved survival after a curative tumour resection is supported by data from Japan. ${ }^{13}$

There is considerable variability and heterogeneity in the clinical course of patients with squamous cell carcinoma of the oesophagus. Beside the TNM classification system additional variables, such as biological staging for the intrinsic malignant potential of the tumours, might be useful for determining long term survival.

Several studies have shown that flow cytometric detection of DNA aneuploidy might reflect the malignant potential of gastrointestinal cancers. $^{2-4}$ Flow cytometry of archival tumour material offers the advantage that long term follow up is available. Comparative studies of fresh and paraffin embedded tumour tissue have shown that accurate determination of DNA ploidy in archival tumour tissue can be performed reliably in most tumours. ${ }^{910}$

In our series, DNA aneuploidy was detected in $61 \%$ of all patients and in $71 \%$ of the unirradiated patients with squamous cell carcinoma of the oesophagus. Because of the known heterogeneity of DNA aneuploidy in oesophageal carcinomas ${ }^{16}$ tumour blocks were analysed until DNA aneuploidy was detected in at least one block or was excluded by measuring all available tumour blocks in one patient. This percentage is 
in accordance with other flow cytometric studies in oesophageal cancer that have reported rates of aneuploidy in the range of $57 \%$ to $91 \%$. Prevalence of DNA aneuploidy was comparable in fresh $\left(83 / 112\right.$ tumours $(74 \cdot 1 \%)^{16-19}$ and in paraffin embedded material $\left(77 / 108\right.$ tumours $(71 \cdot 3 \%) .{ }^{2021}$

The percentage of aneuploid tumours increased according to tumour invasion and the development of lymph node metastasis reflecting an increased genomic instability. ${ }^{17}$ Conflicting results concerning the relation between the degree of differentiation and abnormalities of DNA content have been reported. As in our study, Kaketani et al and Edwards et al did not find a significant correlation ${ }^{21} 22$ whereas this was found by three other groups. ${ }^{17} 1820$

Although a trend for an increased survival time in patients with diploid tumours was found this difference was not significant. These results are supported by the findings from English and Italian groups. ${ }^{2022}$ DNA distribution patterns analysed by cytophotometry, however, have been shown to relate to survival in patients from Japan. ${ }^{23}{ }^{24}$ Because the definitions of DNA aneuploidy differ between these flow cytometric and cytophotometric studies, the results cannot be compared directly. In these cytophotometric studies, aneuploidy was defined by the DNA distribution pattern that was largely determined by cells with DNA values beyond the $4 \mathrm{c}$ region. In flow cytometry, DNA aneuploidy is defined by the presence of a distinct second $G_{0} / G_{1}$ peak.

After preoperative radiotherapy the percentage of aneuploid tumours decreased significantly, from $71 \%$ to $47 \%$. This result should be interpreted cautiously because serial biopsies were not available in these tumours. This result, however, most probably reflects local response to treatment with the eradication of aneuploid tumour cells in a proportion of carcinomas. This interpretation is supported by data in rectal carcinomas. Jones et al showed significant differences in DNA ploidy state between preoperatively irradiated and non-irradiated rectal cancers. ${ }^{25}$ Similar changes were found in serial biopsies taken during radiotherapy in rectal carcinomas. ${ }^{26}$

It has been suggested that aneuploid cervical tumours are more radiosensitive than diploid tumours. ${ }^{27}$ In squamous cell carcinomas of the head and neck and in high grade non-Hodgkin's lymphoma aneuploid tumours are most responsive to chemotherapy. ${ }^{28}{ }^{29}$ In oesophageal cancer, the effect of hyperthermochemo-radiotherapy is more pronounced in aneuploid than in diploid tumours. ${ }^{30}$ Therefore, it can be hypothesised that DNA aneuploidy might be an indicator for response to preoperative radio or chemotherapy. This assumption, however, has still to be supported by prospective studies.

The preoperative radiotherapy did not result in a significant prolongation of survival time. This also applied to the subgroup with a curative tumour resection and is in accordance with other studies that used preoperative radiotherapy. ${ }^{31}$ Although the reduced percentage of aneuploid tumours can be interpreted as a local response to radiotherapy the missing effect on survival points to the fact that oesophageal cancer is often diagnosed at a locally advanced or even dis- seminated stage. In patients who undergo surgery recurrence and death are often attributed to unsuspected early metastatic disease the presence of which has been documented in necropsies performed relatively soon after surgery. ${ }^{32}$

In conclusion, DNA ploidy was not identified as a prognostic factor in oesophageal squamous cell carcinoma in this flow cytometric study. Survival of patients was not improved by preoperative radiotherapy, but was significantly associated with a radical tumour resection. Although the percentage of aneuploid carcinomas was significantly reduced after preoperative radiotherapy this local response did not convert into a prolongation of survival. These results support the necessity of combined modes of treatment including chemotherapy for the eradication of metastatic disease unsuspected at the time of diagnosis.

Dedicated to Professor Dr Georg Strohmeyer on the occasion of his 65 th birthday.

1 Barlogie B, Drewinko B, Schumann J, Göhde W, Dosik G, Latreille $\mathrm{J}$, et al. Cellular DNA content as a marker of neoplasia in man. Am $\mathcal{F}$ Med 1980; 69: 195-203.

2 Armitage NC, Ballantyne KC, Evans DF, Clarke P, Sheffield J, Hardcastle JD. The influence of tumour cell DNA content on survival in colorectal cancer: a detailed analysis. $\mathrm{Br} \mathcal{F}$ on survival in colorectal

3 Schutte B, Reynders MMJ, Wiggers T, Arends JA, Volovics L, Bosman FT, et al. Retrospective analysis of the prognostic significance of DNA content and proliferative activity in large bowel carcinoma. Cancer Res 1987; 47: 5494-6.

4 Yonemura Y, Ooyama S, Sugiyama K, Kamata T, De Aretxabala X, Kimura $\mathrm{H}$, et al. Retrospective analysis of the prognostic significance of DNA ploidy patterns and S-phase fraction in sastric carcion

5 Hedley DW, Friedländer ML, Taylor IW, Rugg CA, Musgrove EA. Method for analysis of cellular DNA content
Medley of paraffin-embedded pathological material using flow of paraffin-embedded pathological material using
cytometry. $\mathcal{F}$ Histochem Cytochem 1983; 31: 1333-5.

6 Stephenson RA, Gay H, Fair WR, Melamed MR. Effect of section thickness on quality of flow cytometric DNA content determinations in paraffin-embedded tissues. Cytometry 1986; 7: 41-4.

7 Vindelov LL, Christensen IJ, Nissen NI. A detergent-trypsin method for the preparation of nuclei for flow cytometric DNA analysis. Cytometry 1983; 3: 323-7.

8 Hiddemann $W$, Schumann J, Andreeff M, Barlogie B, Herman CJ, Leif RC, et al. Convention on nomenclature for DNA cytometry. Cytometry 1984; 5: 445-6.

9 McIntire TL, Goldey SH, Benson NA, Braylan RC. Flow cytometric analysis of DNA in cells obtained from deparaffinized formalin-fixed lymphoid tissues. Cytometry 1987; 8: 474-8.

10 Schutte B, Reynders MMJ, Bosman FT, Blijham GH. Flow cytometric determination of DNA ploidy level in nuclei isolated from paraffin-embedded tissue. Cytometry 1985; 6 : 26-30.

11 Cutler SJ, Ederer F. Maximum utilization of the life-table method in analyzing survival. Foumal Chronic Diseases 1958 8: 699-713.

12 Cox DR. Regression models and life-tables. Fournal of the Royal Statistical Society 1972; 34 (series B): 187-220.

13 Japanese Committee for Registration of Esophageal Carcinoma Cases. Parameters linked to ten-year survival in Japan of resected esophageal carcinoma. Chest 1989; 96: Japan of 11 .

14 Hermanek P, Husemann B, Hohenberger W. The new TNM classification and stage grouping of intrathoracic oesophageal carcinoma. Diseases of the Esophagus 1991; 4: 77-83.

15 Theunissen PHMH, Borchard F, Poortvliet DCJ. Histopathological evaluation of esophageal carcinoma: the significance of venous invasion. BrF Surg 1991; 78: 930-2.

16 Sasaki K, Murakami T, Murakami T, Nakamura M. Intratumoral heterogeneity in DNA ploidy of esophagea squamous cell carcinomas. Cancer 1991; 68: 2403-6.

17 Robaszkiewicz M, Reid BJ, Volant A, Cauvin JM, Rabinovitch PS, Gouerou H. Flow-cytometric DNA content analysis of esophageal squamous cell carcinomas. Gastroenterology 1991; 101: 1588-93.

18 Jin-Ming Y, Li-Hua Y, Guo-Qian, Yan-Tiao C, Xiao L, Wei$\mathrm{Xia} Z$, et al. Flow cytometric analysis DNA content in esophageal carcinoma. Correlation with histologic and clinical features. Cancer 1989;64:80-2.

19 Sanekata $K$, Nishihira T, Kasai $M$. The prognostic value of flow cytometric DNA analysis in human esophageal carcinomas. In: Siewert JR, Hölscher AH, eds. Diseases of carcinomas. In: Siewert JR, Hölscher AH, eds. D
the esophagus. Berlin: Springer Verlag, 1987: 81-4.

20 Ruol A, Segalin A, Panozzo M, Stephens JK, Palma PD, 
Skinner DB, et al. Flow cytometric DNA analysis of squamous cell carcinoma of the esophagus. Cancer 1990; 65: squamo

21 Kaketani K, Saito K, Kobayashi M. Flow cytometric analysis of nuclear DNA contant in esophageal cancer. Aneuploidy as an index for highly malignant potential. Cancer 1989; 64:

22 Edwards JM, Jones DJ, Wilkes SJL, Hillier VF, Hasleton PS. Ploidy as a prognostic indicator in oesophageal squamous carcinoma and its relationship to various histological criteria. F Pathol 1989; 159: 35-41.

23 Sugimachi K, Ide H, Okamura T, Matsuura H, Endo $M$, Inokuchi $\mathrm{K}$. Cytophotometric DNA analysis of mucosal and submucosal carcinoma of the esophagus. Cancer 1984; 53: 2683-7.

24 Matsuura H, Kuwano H, Morita M, Tsutsui S, Kido Y, Mori $M$, et al. Predicting recurrence time of esophageal carcinoma through assessment of histologic factors and DNA ploidy. through assessment of his

25 Jones DJ, Zaloudik J, James RD, Haboubi N, Moore M, Schofield PF. Predicting local recurrence of carcinoma of the rectum after preoperative radiotherapy and surgery. $\mathrm{Br} \mathcal{F}$ Surg 1989; 76: 1172-5.
26 James RD, Schofield PF. The value of radiotherapy for rectal cancer. Baillieres Clin Gastroenterol 1989; 3: 647-69.

27 Dyson JED, Joslin CAF, Rothwell RI, Quirke P, Khoury GG Bird CC. Flow cytometric evidence for the differential radioresponsiveness of aneuploid and diploid cervix tumours. Radiother Oncol 1987; 8: 263-72.

28 Cooke LD, Cooke TG, Bootz F, Forster G, Helliwell TR Spiller $\mathrm{D}$, et al. Ploidy as a prognostic indicator in end stage squamous cell carcinoma of the head and neck region treated with cisplatinum. $\mathrm{Br} F$ Cancer 1990; 61: 759-62.

29 Morgan DR, Williamson JMS, Quirke P, Clayden AD, Smith MEF, O'Brien CJ, et al. DNA content and prognosis of nonHodgkin's lymphoma. Br 7 Cancer 1986; 54: 643-9.

30 Ohno S, Korenaga D, Kuwano H, Mori M, Sugimachi K. DNA aneuploidy assessment of the effectiveness of hyperthermo-chemo-radiotherapy for esophageal carcinoma. Cancer 1989; 63: 1951-5

31 Gignoux M, Roussel A, Paillot B, Gillet M, Schlag P, Favre JP, et al. The value of preoperative radiotherapy in esophageal cancer: results of a study of the EORTC. World $\mathcal{f}$ Surg 1987; 11: 426-32.

32 Sons HU, Borchard F. Esophageal cancer. Autopsy findings in 171 cases. Arch Pathol Lab Med 1984; 108: 983-8. 